MYERS, R. D.. \& SHARPE, L. G. Chemical activation of ingestive and other hypothalamus regulatory mechanisms. Phvsiology \& Behavior, 1968, 3, 987-995.

NANCE, D M. Neurobehavioral correlates of intracranial chemical stimulation of the cat. Unpublished PhD thesis, Oklahoma State University, 1969.

SHARPE. L. G. Chemical stimulation of the diencephalon of the rhesus monkey (hacaca mulatta) Unpublished PhD thesis, Purdue University, 1969.

SHUTE, C. C. D., \& LEWIS, R. $P$. Cholinergic and monoaminergic pathways in the hypothalamus. British Medical Bulletin, 1966, 22, 3, 220-226.

SIEGEL, S. Nonparametric statistics for the behavioral sciences. New York: McGraw-Hill, 1956.

\title{
The specificity of social attraction in rats*
}

\author{
BIBB LATANÉ \\ The Ohio State University, Columbus, Ohio, 43210 \\ and \\ EMILY SCHNEIDER, PETER WARING, and RICHARD ZWEIGENHAFT \\ Columbia University, New York, N.Y. 10027
}

Rats housed alone or in pairs were tested daily with either the same partner or with a stranger. All rats were highly and increasingly attracted to each other, but they were not more attracted to familiar rats than to strangers. Isolated animals became more gregarious than pair-housed rats by the fourth day of testing. In Experiment 2, rats tested in trios with a stranger and a cagemate again showed no preference. The results indicate that rats do not develop specific attachments.

A series of recent studies has shown that the lowly albino rat is a highly gregarious organism. When tested in pairs in an open field, rats stay much closer to each other than would be expected by chance (Latane, 1969), or than to a variety of nonsocial objects (Latané \& Glass, 1968). With repeated testing, gregariousness increases. Typically, over $90 \%$ of all rat pairs were more affiliative on the last day of testing than on the first. In part, this is probably because exploratory

* This research was conducted at Columbia University and supported by grants from the National Science Foundation (GS 1239 and GS 2292) and the Columbia University Council for Research in the Social Sciences. Requests for reprints should be sent to Bibb Latané, Department of Psychology, The Ohio State University, $404-C$ West 17 th Avenue, Columbus, Ohio 43210 . responses, which compete with sociability in an unfamiliar environment, tend to drop out as rats become familiar with the open field (Eckman, Meltzer, \& Latané, 1969). In part, however, it may be due to the development of specific attachments between rats. It is the purpose of the present experiments to test this latter possibility.

\section{EXPERIMENT 1} Overview

Animals were housed either alone or in pairs and tested either with the same animal each day or with a stranger each day. If rats do develop specific attachments, we should expect to see cagemates more attracted to each other than to strangers, and rats tested daily with the same partner more attracted than rats tested with a different partner each day.
Subjects and Apparatus

Fifty-four naive male Sprague-Dawley rats (Carworth Farms) were 40 days old at the start of testing. They had arrived in the laboratory at 23 days of age and were housed in group cages, 12 to a cage, until they were 35 days old, at which time they were assigned randomly to new housing conditions. Food and water were always available ad lib.

Rats were tested in a circular wooden 4-ft-diam open field surrounded by an 18 -in. wall. The field was painted flat white, and the floor was marked by black lines into 49 numbered areas of equal size and equivalent shape (Latané, 1969). A $150 \cdot \mathrm{W}$ bulb was suspended $5 \mathrm{ft}$ above the center of the open field.

Experimental Conditions

Rats were assigned randomly either to isolated (14 pairs) or paired (13 pairs) housing conditions 5 days before the start of testing. Isolated animals lived alone in $10 \times 7 \times 5$ in. metal cages with wire mesh fronts and bottoms, and could thus smell and hear other rats. Paired animals lived in pairs in the same cages and thus had ample opportunity to become familiar with each other.

Within each housing condition, rats were assigned randomly either to same-partner or different-partner testing conditions. Rats in the different-partner conditions were tested with a different rat (always from the same housing condition but never their cagemate) each day, so their testing partner was always unfamiliar to them, $R$ ats in the same-partner condition were always tested with the same partner (their cagemate, if they were in the paired housing condition) each day, so they had opportunity to develop specific "friendships."

\section{Procedure}

Rats were tested $5 \mathrm{~min}$ a day for 4 consecutive days in the open field. Rats were placed in pairs in the open field, and their locations recorded at 10-sec intervals. The mean distance between the two rats over the 30 10 -sec periods was computed from the recorded locations and could range from 0 to $40 \mathrm{in}$., the lower scores indicating higher gregariousness. At the end of each trial, the field was swabbed with a damp cloth. Results

Overall, rats were quite gregarious. Every pair stayed closer together than would be expected if their movements in the open field were entirely uninfluenced by each other. Compared to a "chance" distance of about 24.8 in. (Latané, 1969), rats averaged only 16.0 in. $(p<.001) .1$

As in previous experiments, rats became more gregarious over days 
(Fig. 1). On the first day, the average separation was 19.5 in, ; by the last, it was only 13.0 in. $(p<.001)$. Twenty-three of the 27 pairs were closer on the last than on the first day of testing.

This increase in attraction clearly was not due to increasing familiarity with the testing partner. Rats always tested with a strange rat were just as gregarious and increased just as much in gregariousness as rats always tested with the same partner. Rats in the former condition maintained an average distance of $16.0 \mathrm{in}$., rats in the latter, 15.9 in. (n.s.).

The main effect of housing was not significant, and it did not interact significantly with testing condition. There was a tendency, however, for isolated animals to be somewhat and increasingly more affiliative than paired animals, contrary to the suggestion that social contact leads rats to learn to like each other (Fig. 1). By the fourth day of testing, isolated rats were significantly more affiliative than were paired animals $(p<.02)$. This effect of housing experience has been found in a number of subsequent studies (Cappell \& Latané, 1969; Latané, Cappell, \& Joy, 1970) and seems to indicate that rats are susceptible to social deprivation.

\section{Discussion}

Social contact, whether in the home cage or in the open field, did not lead to increasing sociability. Failure to find such a difference cannot be attributed to insensitivity of the dependent measure, since day of testing had strong and easily detectable effects. The results, then, suggest that the days effect found in previous experiments cannot be accounted for by the development of specific attachments. The days effect in the present experiment was just as powerful when there was no opportunity for specific attachments between individual animals to develop as when there was such an opportunity.

This does not necessarily mean, however, that specific attachments do not or cannot develop in rats. Although it was true that paired rats were somewhat less sociable than isolated rats, this may be because social deprivation outweighed specific friendships. In Experiment 2, rats were tested with their cagemates and wii: noncagemates who also lived in pairs.

\section{EXPERIMENT 2}

Methods

Thirty-six naive female rats were housed two to a cage for 6 days, starting at the age of 40 days. All 18 pairs were provided with ad lib food and water. On Days 7-12, 12 trios of rats were tested in the open field for

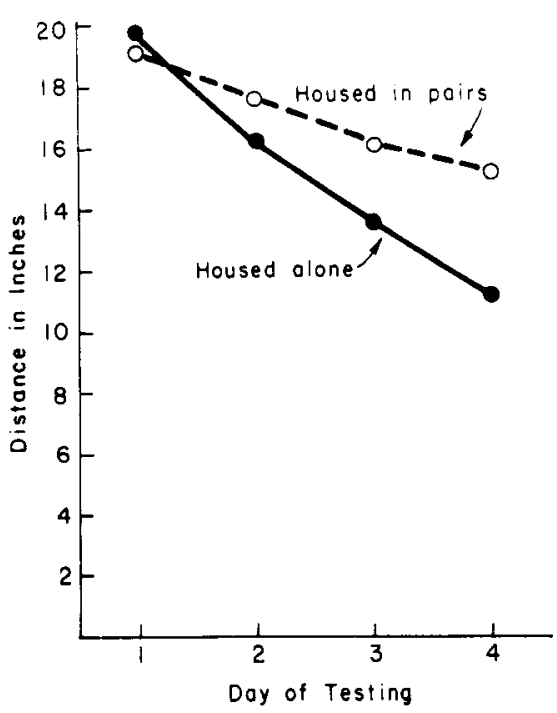

Fig. 1. Average distance in the open field between rats housed alone and rats housed in pairs.

5 min each. Each trio consisted of two rats which had been housed together and one which had been housed with another rat.

During testing, the position of each rat was recorded every $10 \mathrm{sec}$. The distance between each pair of rats during testing was computed from these recorded locations. If the tendency toward affiliation is specific and discriminatory, the distance between cagemates should be less than that between strangers. If affiliation is nonspecific and indiscriminate, however, the distances between the three pairs should be approximately the same.

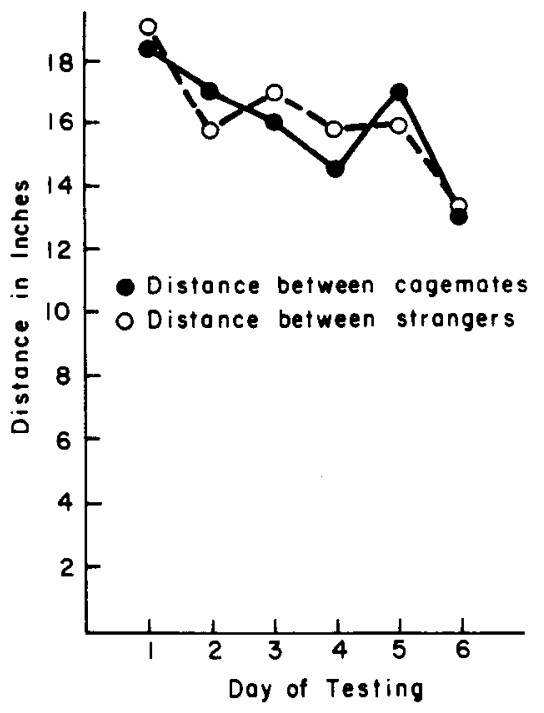

Fig. 2. Average distance in the open field between cagemates and strangers when tested together in trios.
Results

Cagemates averaged no more and no less distance apart than did strangers. As Fig. 2 shows, although the distance between all rats decreased over days (thus confirming earlier findings), the cagemates stayed no closer to one another (16.2 in.) than did the strangers (16.1 in., n.s.).

Discussion

Carr and his associates (Carr, Loeb, \& Dissinger, 1965; Carr, Loeb, \& Wylie, 1966; Carr, Wylie, \& Loeb, 1966) have shown that sexually active rats prefer the odor of sexually active rats to the odor of nonreceptive or castrated rats, while Sharpe \& Cooper (1966) have shown that rats can be trained (by use of food and shock) to avoid a cringing stimulus rat in favor of a normal rat. The present results suggest, however, that in the absence of sexual or shock-avoidance motivation, rats do not normally discriminate among other rats of the same age or sex.

This result would seem to indicate that social attraction in rats is not based on the formation of specific attachments between animals, but on a more general liking for other rats. It is possible that this could be because most rats look alike, even to other rats, but more likely it is because most rats are equally able to satisfy each other's needs for social contact and interaction.

\section{REFERENCES}

CAPPELL, H., \& LATANE, B. Effects of alcohol and caffeine on the social and emotional behavior of the rat. Quarterly Journal of Studies on Alcohol, 1969, 30, 345-346.

CARR, W. J., LOEB, L. S., \& DISSINGER, M. M. Responses of rats to sex odors. Journal of Comparative \& Physiological Psychology, 1965, 59, 370-377.

CARR, W. J., LOEB, L. S., \& WYLIE, N. R. Responses to feminine odors in normal and castrated male rats. Journal of Comparative \& Physiological Psychology, $1966,62,336-338$

CARR, W. J., WYLIE, N. R., \& LOEB, L. S. The effect of early experience on the response to sex odors by immature rats. American Zoologist, 1966, 6, 73 .

ECKMAN, J., MELTZER, J., \& LATANÉ, B. Gregariousness in rats as a function of familiarity of environment. Journal of Personality \& Social Psychology, 1969. 11, 107-114.

LATANÉ, B. Gregariousness and fear in laboratory rats. Journal of Experimental Social Psychology, 1969, 5, 61-69.

LATANE, B., CAPPELL, H., \& JOY, V. Social deprivation, housing density and gregariousness in rats. Journal of Comparative \& Physiological Psychology, $1970,70,221-227$

LAT ANE, B., \& GLASS, D. C. Social and non-social attraction in rats. Journal of Personality \& Social Psychology, 1968, 9, 142-146.

SHARPE, L. G., \& COOPER, J. B. Interindividual recognition in albino rats. Journal of Genetic Psychology, 1966, 109, 151-161.

NOTE

1. All $p$ values are based on two-tailed tests. 